\title{
The use of violence in cargo theft - a supply chain disruption case
}

\author{
Daniel Ekwall $^{1,2}$ (D) Björn Lantz ${ }^{3}$
}

Received: 16 December 2016 / Accepted: 3 January 2018 / Published online: 18 January 2018

(C) The Author(s) 2018. This article is an open access publication

\begin{abstract}
This paper examines patterns of reported cargo thefts involving violence in the Europe, Middle East, and Africa region with regard to the value of stolen goods, incident frequency, transport chain location, and incident category. The research method is deductive and is based on analyses of secondary data obtained from the Incident Information Service by the Transported Asset Protection Association. The results are discussed within a frame of reference based on supply chain risk management and supply chain disruption literature. We found that perpetrators who use violence seem to cause greater losses per theft than those who use other types of modus operandi. Further, the most common type of violent cargo theft occurs on Mondays in January when cargo vehicles are robbed on the road and consumer electronics are stolen. In terms of supply chain disruption, violent cargo thefts can be seen as externally-caused disruptions, which can indirectly cause major problems for the supply chain.
\end{abstract}

Keywords Hijack · Robbery · Transport chain - Violence in cargo theft - Supply chain disruption

\section{Introduction}

There are two main features of a hijacking of goods transported by road, namely violence and timing. According to an example from the French Police (OCLDI), the following is a typical hijacking: Once the truck or van has been forced into stopping (by

Daniel Ekwall

Daniel.Ekwall@hb.se

1 Faculty of Textiles, Engineering and Business, University of Borås, 50190 Borås, Borås, Sweden

2 Supply Chain Management and Social Responsibility, Hanken School of Economics, 00101 Helsinki, Finland

3 Division of Operations Management, Chalmers University of Technology, 41296 Gothenburg, Sweden 
a car or a van blocking the road), the drivers are pulled out of the vehicle and very often taken hostage or even physically assaulted. The hijacked truck or van is then driven by the perpetrators to a nearby hiding place where another truck or van is waiting, and the products are immediately unloaded onto the truck or van. Normally, the stolen truck or van is then set on fire, and the hijacked drivers are released shortly thereafter in remote locations (FWI SCIC 2015).

According to van Marle (2015), violent cargo crimes are on the rise in Europe, especially in France, Italy, and Russia. Furthermore, FreightWatch reports that of the top ten freight crime hotspots in Europe, seven will see an increase in violent thefts and hijackings in the future (van Marle 2015). Cargo thefts in the greater Paris area are a good example as these crimes are three times more likely to involve violence as compared to cargo thefts in other parts of France. Another key component is that the attack normally happens within just a few kilometers of the consignor or consignee's terminal (van Marle 2015). This type of hot spot is normally referred to as "around the corner" (cf Ekwall and Lantz 2016).

Both of these descriptions of violent cargo thefts signal a few interesting features. First, potential perpetrators have determined during the planning stages of certain cargo thefts to use violence. Second, there are differences across Europe in terms of how violence is used and in terms of transport chain locations, including where the shipment is targeted.

In addition to the direct effect of cargo loss as a result of such thefts, there is a disruptive effect due to the violent modus operandi. For example, in September 2014, following several violent thefts on delivery vehicles within a short period, a logistics service provider (LSP) invoked a force majeure clause in accordance with liability regulations (Karlsson 2014). This led to all scheduled deliveries within a certain geographical area in Stockholm being temporarily stopped and delayed for a few days. Thus, violent thefts against delivery vehicles cause a geographically-linked supply chain disruption.

This paper will address two of the three aforementioned features, namely the use of violence in relation to the value of stolen products in cargo theft incidents. The third issue, which relates to insurance policies and regulations and the role of insurance providers, will only be addressed in this paper in the context of violent theft.

According to Ekwall and Lantz (2013), cargo theft is a crime generally characterized by seasonal effects. These effects may be related to calendar elements like time-of-year, time-of-week, and even time-of-day. Such effects imply a non-constant theft endangerment over the year, month, or day. For example, business representatives often talk about the "Christmas rush" in cargo theft, referring to an increase in thefts linked to Christmas sales (Ekwall and Lantz 2013). The loss of a truck loaded with expensive consumer electronics a few weeks before Christmas can, of course, have a substantial impact on the regional market. However, there is no prior research on seasonal patterns in violent thefts. Hence, the main research question in this study is: Are violent cargo crimes characterized by seasonal effects?

\section{Research purpose}

The purpose of this study is to explore patterns of reported cargo thefts involving violence in the Europe, Middle East, and Africa (EMEA) region with respect to the 
value of stolen goods, incident frequency, transport chain location, incident category, and modi operandi (MO). The study's results have implications for researchers and practitioners as cargo theft incidents lead to a disruption in the flow of goods.

\section{Background}

The theft of goods poses a significant problem across the globe. Cargo theft represents a value that the European Union (EU) estimates as $€ 8.2$ billion annually. In the context of all cargo transportation, this is an average of $€ 6.72$ per trip. However, these figures are conservative because most cargo thefts go unreported and because the figures reflect only the value of the items stolen. Further, collecting accurate data for cargo theft losses is either difficult or impossible in many cases because of limited reporting by the transportation industry and the lack of an international law enforcement system that could ensure consistency in reporting and tracking (ECMT 2001).

In addition, the insurance business faces difficulties distinguishing fraud from actual theft; but even if it had the correct figures for theft, it would not share these with the public due to concerns over trade secrets and competition. Moreover, despite the aforementioned figures, general cargo theft is regarded as low priority in most countries and is often largely perceived as a cost of doing business (EU 2003). Nevertheless, research shows that cargo theft poses a serious threat to modern trade (EP 2007). The reporting of violent cargo theft would, from a theoretical perspective, represent most of the actual incidents because this type of modus operandi involves someone being threatened or even killed, a situation which leads to a greater willingness to report and to more attention from authorities. Therefore, the official statistics for this type of theft are likely to be more accurate. However, the problem with insurance fraud remains, even if it is arguably more difficult to stage such a fraud than an actual theft.

General statistics on cargo theft provide that about $41 \%$ of all incidents occur during the driving phase of transportation and involve threats against the driver or tearing the canvas of the load unit. In $15 \%$ of incidents, the vehicle is stolen along with the goods. Another 15\% represents hijackings and robberies (EP 2007). According to a report by the International Road Transport Union (IRU) (2008), vehicles and their loads were targeted in $63 \%$ of all thefts, while $43 \%$ were either direct thefts of transported goods or included theft of the drivers' personal belongings. Of these thefts, $42 \%$ occurred in vehicle parks and $19 \%$ on motorways (IRU 2008). This means that $61 \%$ of all thefts occurred at a temporary stopping place along a road. The targets of cargo theft are typically vehicles that are temporarily parked along the roadside, often waiting for loading and unloading opportunities (EP 2007; TruckPol 2007; IRU 2008). In this context, prior research has shown that a violent $\mathrm{MO}$ has a greater impact (in terms of the higher value of the stolen goods) than average (Ekwall and Lantz 2013; Ekwall and Lantz 2015a; Ekwall and Lantz 2015b).

This paper focuses on the use of violence from the perpetrator's perspective, and the aforementioned elements will serve as the basis for understanding crime. In criminology, violent crimes are crimes in which the perpetrator uses or threatens force against a victim. Depending on local legislation, violent crimes can be anything from murder to robbery, even harassment. A violent crime may include the use of a weapon, although this is not required. Comparing statistics and knowledge about violent crimes is difficult because different legislation and practices means that the interpretation of 
figures and facts is inconsistent. Normally, the homicide index (the number of homicides per 100,000 citizens annually) is used as a good indicator of the general danger in a region or country. In most EU countries, this index is between one and two (UN-CTS 2010), and this is considered a moderate or even low index number. The general crime trend in the EU is that crime is declining from its peak in 1995. However, according to Tavares and Thomas (2009), there was an increase in reported types of violent crime (up 3\%) and drug trafficking and robbery (both up 1\%) during 1998-2007. During the same period, there has been a decrease in motor vehicle theft (down 7\%) and domestic burglary (down $3 \%$ ). There seems to be a time difference among countries; however, the overall trend is nevertheless declining, and crime patterns are surprisingly similar among member states (van Dijk et al. 2006). In sum, the general EU trend for violent crime is slightly increasing, although murder is slightly decreasing.

According to the IRU (2008), $17 \%$ of all cargo vehicle drivers have been robbed in the past five years, and $30 \%$ of the robbed drivers have experienced more than one theft. Further, $21 \%$ of the robbed drivers reported that they were physically assaulted (IRU 2008). In addition, 10\% of all freight crimes are hijackings (IRU 2008). These statistics illustrate the presence of violent crimes for road transportation within the EU. According to Ekwall and Lantz (2013), the majority of cargo thefts are low impact because the perpetrators steal goods of relatively small value. In addition, the majority of the thefts occur away from transportation facilities in places such as non-secured parking, secured parking, and en route. These account for $78 \%$ of all incidents, yet only $57 \%$ of the loss value (Ekwall and Lantz 2013). This could indicate that potential perpetrators consider the security at facilities to be generally higher than the security in areas outside of such facilities. Thus, if potential perpetrators steal goods from facilities, they need to make better plans or be prepared to use another MO, such as violence, in order to succeed.

A violent $\mathrm{MO}$ is not unusual among thieves in retail stores either. Inventory loss due to criminal behavior in retail stores is estimated to be more than 24 billion Euros annually (Bamfield 2004). According to BRC (2009) violent attacks against retails stores in the UK cost (losses plus prevention) 2.4 billion pounds annually. Furthermore, the cost itself is not the only problem, as violent attacks against retail staff doubled between 1996 and 2001 (Lawrence 2004). The typical perpetrator is described as a drug abuser stealing between $£ 22,000$ and $£ 44,000$ annually (ibid). Similar to theft of goods during transport, a relatively small number of thefts causes the majority of losses while the majority of thefts corresponds with relatively low loss values (Bamfield 2006).

From the perpetrators' perspective, the value of stolen goods needs to be higher in order to cover the extra risk. According to Saunders (2008), it is possible that "some perpetrators respond to sophisticated transport security measures by increasing their use of unsophisticated and brutal violence against drivers and terminal personnel." A similar development was expressed by European Parliament (2007): "The criminal organisations seem to react to the increase of security with more aggressive methods." In other words, violence can be used to steal more goods (of a greater total value) during any individual theft or used as a way to overcome security features.

In order to provide a better understanding of the use of violence in cargo theft, this paper uses criminological theories in combination with logistics theories and actual data about cargo theft from the Incident Information Service (IIS) of the Transported Asset Protection Association (TAPA) in the EMEA. Therefore, an interdisciplinary approach 
to views, ideas, and theories is employed, as required when developing applied science research (Stock 1997).

\section{Frame of reference}

Research in supply chain risk management (SCRM) is receiving an increasing amount of interest from practitioners and scholars. Colicchia and Strozzi (2012) propose a comprehensive risk management and mitigation model for global supply chains, while Manuj and Mentzer (2008) argue that the risk of any particular type of loss should be conceptualized as the probability of the loss multiplied by its impact. Similar definitions of risk can be found in most contemporary research on SCRM (Norrman and Jansson 2004; Khan and Burnes 2007; Wagner and Bode 2008; Tummala and Schoenherr 2011, Ghadge et al. 2013). Thus, from this perspective, risk should be considered as a combination of the probability or frequency of a certain hazard's occurrence and the value or impact of its occurrence. In this paper, we use the reported occurrence of a violent modus operandi for cargo theft, together with the reported impact.

\section{Supply chain disruption}

In any supply chain setup, there can be a wide variety of disruptive events, such as transportation delays, port stoppages, accidents and natural disasters, poor communication, part shortages, quality issues, and operational issues (Chapman et al. 2002; Machalaba and Kim 2002; Mitroff and Alpasan 2003; Ghadge et al. 2013). The key issue is that if one link in the chain fails to fulfill its intended purposes, the entire chain will fail (Rice and Caniato 2003). Furthermore, the disruptive event has the potential to be passed onto another tier in the chain, with potential amplification effects. The real danger is not found in long-term changes like customer demand - although that may threaten the company's existence - but rather, it is found in random fluctuations that can affect large parts of a certain supply chain causing major management problems. Interestingly, there has been relatively little research within the area of SCM to understand disruptions of supply chains.

According Mitroff and Alpasan (2003), only 5-25\% of the largest companies have plans to handle crises or disruptions. Furthermore, according to Riddalls and Bennett (2002), disruptions can be costly in supply chains, such as long lead-times, stock-outs, and more importantly, inability to meet customer demand. Levy (1995) states that disruptions can lead to unexpected costs when shipping lead-times are long. More importantly, Levy (1995) found that managers address crises as one-time events instead of considering the lack of robustness in their own supply chain. One of the biggest research problems in this area is the lack of cost estimations for supply chain disruptions. Only a few attempts have been made to estimate these costs, and Rice and Caniato (2003) estimate a daily cost for disruptions as 50-100 million US dollars.

According to $\mathrm{Wu}$ et al. (2007), uncertainty is the key issue in supply chain disruptions as disruptions are caused by unexpected events. These events can be uncertain in many different ways, but they all negatively affect the flow of goods through the supply chain. The sources of these unexpected events may be poor quality (in general), failing supply due to new import/export regulations, and criminal 
activities. Uncertainty in supply chains is a well-researched topic. According to Wilding (1998), uncertainty is generated within the supply chain as a result of the design and operation of the system instead of external sources. Similar approaches to uncertainty can be found in most contemporary research (Van der Vorst and Beulens 2002; Vidal and Goetschalckx 2000; Muralidharan et al. 2001; Ghadge et al. 2013; Lee and Rha 2016), which indicates that uncertainty is primarily addressed or reduced through safety buffers in time, capacity, and inventory. One interesting view on SCD is that understanding managerial behavior in SCD scenarios and the managerial decision-making process is important for understanding the long-term impact of an SCD (Lorentz and Hilmola 2012). The general strategy with SCD is to better manage the supply chain system to handle disruption risks, while still having the traditional logistics/SCM advantage of low costs and inventory levels and greater flexibility and agility, and also having the ability to reduce amplifications of bullwhips or domino effects throughout the chain (Wu et al. 2007; Lorentz and Hilmola 2012).

In most papers discussing SCD, the external unexpected event of violent cargo theft is not even mentioned. To be clear, crime in general is not really addressed as a source of disruption, even though billions are lost annually due to criminal attacks towards the international flow of goods (EU 2003; EP 2007). This paper uses a risk management approach within SCD to understand the loss of goods due to violent attacks in order to reduce the gap in the current research.

\section{Crime seasonality}

Criminology research posits that crime is a somewhat seasonal phenomenon. Cohen (1941) argues that there are two types of seasonality at the local level: (1) crimes against property (burglaries, robberies, and thefts), and (2) crimes of aggression (assaults, homicides, and rapes). These two general theories on seasonality have emerged from prior research: the temperature aggression hypothesis and the needsbased view of property crime (Falk 1952). The latter suggests that seasonal unemployment and living expenses influence the level of criminal activity at different times of the year (Gorr et al. 2003); thus, non-violent crimes are more frequent during the autumn and winter, and violent crimes (such as hijacking and robbery) are more common during the summer.

The temperature aggression hypothesis (i.e., that hot temperatures cause an increase in aggressive and violent crimes) has been supported by laboratory and field experiments, correlational studies, and archival studies of violent crimes (Anderson et al. 2000). In terms of seasonality, studies that compare regional violence rates all support the conclusion that hot years, seasons, months, and days contribute to the use of violence in crimes (Anderson et al. 1997). According to Anderson et al. (1997), even global warming can lead to an increase in the violence used in crimes. In this paper, we only address the temperature aggression hypothesis because we focus on violent cargo theft. In other words, we consider whether there is seasonal variation (an increase during the summer) for a violent modus operandi (hijacking and robbery).

According to Hylleberg (1995), the exogenous causes of crime, namely calendar events, weather, and time of year, are important for understanding seasonality because they can lead to an increase or decrease in criminal behavior depending on local contextual circumstances. The time of year (e.g., during the Christmas shopping 
season) can influence criminal opportunities in various ways (Gorr et al. 2003). Consequently, the seasonality of crimes can be influenced by the time of year depending on the number of targets available and the potential customers for stolen goods. For similar reasons, seasonality can also be linked to calendar events such as the day of the week. However, in this case, seasonality largely depends on the number of available targets. Nevertheless, such seasonality of crimes aids crime forecasting (Gorr et al. 2003) and the use of security measures as a proactive response to an expected increase in crime.

\section{Hypotheses}

Based on the literature review, our overall supposition is that there are seasonal patterns in the use of violence in cargo theft. This supposition can be broken down into four testable hypotheses, which are listed below:

H1: Incident values for violent cargo theft differ across months.

$\mathrm{H} 2$ : Incident frequencies for violent cargo theft differ across months.

H3: Incident values for violent cargo theft differ across days of the week.

H4: Incident frequencies for violent cargo theft differ across days of the week.

\section{Method}

\section{The TAPA EMEA IIS database}

The TAPA EMEA IIS database, which was analyzed in this paper, comprises approximately 20,000 individual reported incidents of road transportation crimes committed between 2000 and 2011 within the EMEA area. The crime statistics in the TAPA EMEA IIS database are prepared by TAPA members and various law enforcement agencies (LEAs) in the EU. The identities of the companies involved, directly and indirectly, are not disclosed in the reports in order to avoid negative publicity and ensure better data reliability. Further, the reporting entity determines the extent of disclosure of the incident details, thus suggesting that the quality of data varies across incidents and countries. Nevertheless, the TAPA EMEA IIS database is considered the most accurate database in the EU for crime incidents (Europol 2009). The reporting procedure ensures that the database presents a true picture of cargo theft incidents in terms of absolute numbers and trends. The global TAPA structure enables the data to be limited to the EMEA region because there are three TAPA regions (the Americas, EMEA, and Asia-Pacific), each of which has its own IIS database. Within the EMEA region, the vast majority of the data is for countries in Northern and Western Europe. Consequently, the data cover the same seasonality (time of year); that is, the seasons of the northern hemisphere.

Reports for the database are generally created using the online reporting interface at www.tapaemea.com. The reports include a number of mandatory facts such as the reporting person (name with contact details), incident date, and description. Further, there are a number of fixed descriptions about the incident in the following categories: incident type, modus operandi, type of location, country of occurrence, and product and 
loss value in euros. It is also possible to add more data to the report. This paper uses the data in the fixed description fields for violence related to cargo theft.

\section{Research method}

Risk is a concept related to the future. Past events, by definition, are not risky because there is certainty about what has already happened. However, historical data can often be used to analyze future risks related to past specific events. Therefore, in this paper, we use historical incident frequencies to estimate the probability of future incidents, and historical incident values to estimate the impact of future incidents. We have only used secondary data and in this regard we follow the reasoning of Rabinovich and Cheon (2011). They argue that the importance of secondary data analysis has been overlooked in logistics research and that it should be used to address the contemporary challenges in logistics and supply chain research.

The use of secondary data in this paper provides high internal validity and a good opportunity to replicate this study (Rabinovich and Cheon 2011). The paper follows the tradition of logistics research by using a systematic approach to understand the problem from a holistic perspective while focusing on the interactions among components rather than the causes (Aastrup and Halldórsson 2008). We describe and analyze the values and frequencies of incidents using relevant statistics. The analyses are based on the logarithm of the incident value after standardizing for the length of the month. Further, in order to compare the mean values, we use a one-way ANOVA when the Levene's test does not reveal significant heteroscedasticity and the Brown-Forsythe test when it does. If either the ANOVA or Brown-Forsythe test is rejected, a post-hoc analysis is conducted using pairwise t-tests with the Bonferroni correction or Tamhane's T2. The frequencies among the various groups are compared using the chi-square test. If the test is rejected, a post-hoc analysis is conducted using pairwise chi-square tests with the Bonferroni correction.

When the data are closer to a census than to a random sample, the results of regular significance tests are less valuable because the observed parameters coincide with the actual population parameters in a true census. Because our data are drawn from a census of incidents reported between 2000 and 2011, our descriptive statistics can be considered as actual population parameters. However, because we use this data to study the future of transportation security, the data should be considered as a consecutive sample and hence be subject to significance testing.

\section{Incident categories for cargo theft}

\section{Typology of road cargo theft incidents}

The definition of road cargo theft used in this paper is the same as that used by the TAPA EMEA IIS database and by the European Police Office (Europol) (2009): any theft of a shipment during road transportation or within a warehouse, but excluding internal petty theft. Further, the incident category definitions (Europol 2009) are as follows:

- Hijacking: force, violence, or threat is used against the driver, and the vehicle and/ or goods are stolen. Hijacking includes forcibly stopping a vehicle. 
- Robbery: force, violence, or threat is used against individuals, and the vehicle and/ or goods are stolen. Robbery does not include forcibly stopping a vehicle.

- Theft: goods are stolen.

- Theft of: an unattended vehicle and/or trailer are stolen along with their loads.

- Lorry theft: a lorry (a vehicle carrying cargo) is stolen but not its cargo.

- Theft from vehicles: theft of loads from stationary vehicles (e.g., by curtain slashing) or from delivery vehicles left unlocked/unattended, or theft from a facility.

- Deception/Diversion: drivers or companies are deceived into delivering to a destination other than the one intended (commonly referred to as "around the corner"); this includes "e-crimes" whereby bogus logistics companies are established to divert deliveries.

- Fraud: individuals are intentionally deceived and a vehicle and/or goods are stolen.

- Burglary: burglary in commercial premises that are part of the supply chain in all of the above cases.

The MO categories are listed below:

- Deception: drivers or companies are deceived into delivering to a destination other than the one intended (commonly referred to as "around the corner"); this includes "e-crimes" whereby bogus logistics companies are established to divert deliveries.

- Deceptive stop: a deceptive method is used to stop a vehicle without the use of violence or force.

- Forced stop: force, violence, or threats are used against a driver, and the vehicle or goods are stolen. Hijacking is a form of forced stop.

- Internal: thefts are committed by employees belonging to either the logistics companies or one of the players in the supply chain.

- Intrusion: incidents where perpetrators "break" their way to the goods. Burglary is a form of intrusion.

- Pilferage: a theft wherein the value or the quantity of the stolen goods is low.

- Violent: incidents where force, violence, or threats are used against a driver or terminal workers, and the vehicle or goods are stolen. Robbery is considered a violent crime.

This paper uses the following six categories for transport chain location (consistent with how data are stored in the TAPA EMEA IIS database):

- Non-secured parking: the theft occurs in a non-secured parking area.

- Secured parking: the theft occurs in a secured parking area.

- Third-party facility: the theft occurs at a third-party facility or warehouse.

- En route: the theft occurs when the vehicle is moving. This may include a forced stop.

- Transport mode facility: the theft occurs on a specific mode of transport (aviation, maritime, road, rail) or at a specific facility or terminal.

- Supply chain facility: the theft occurs at either a consignor's or a consignee's facility (the owner of a goods facility). 
In this paper, we focus on violent cargo crimes. This means that the data used from the TAPA EMEA IIS database is either from the "violent" MO or the incident categories of "robbery" and "hijacking."

\section{Results}

Table 1 displays the descriptive statistics of all reported thefts within the TAPA EMEA IIS database for 2000-2011. As expected, there are large differences between the years. For example, there are significantly larger numbers of reports for 2006-2010. This suggests that any single year of statistics is not representative of the cargo theft problem. The large differences could indicate a similarly large difference in the hidden statistics of cargo theft reports. In addition, according to the IRU (2008), 30\% of drivers did not report thefts to the police. This percentage figure is supported by the European Conference of Ministers of Transport (ECMT) (2001) and other reports in the field. However, despite this, the data in Table 1 show that violence is a less frequent problem, although it is involved in $2-19 \%$ of all thefts with a mean of around 5-6\%. In this context, it is important to remember that the hidden statistics should reflect fewer violent crimes because the methods used generally require eyewitnesses to violence and threats. There is insignificant support for this claim in Table 1 because as the annual total of reported thefts increases, the relative share of violent thefts decreases.

Table 2 displays descriptive statistics for different months. As expected, there are large differences between the months. Hence, a more comprehensive analysis is needed. A Levene test reveals significant heteroscedasticity in the mean incident values $(\mathrm{L}=3.7002, p<0.001)$. Thus, a Brown-Forsythe test is used to compare the mean values across months, but no significant difference is found $(\mathrm{F}=1.216, p=0.277)$.

Table 1 Descriptive statistics of reported thefts for 2000-2011 in the TAPA EMEA IIS database

\begin{tabular}{llll}
\hline Year & $\begin{array}{l}\text { Total number } \\
\text { of reported thefts }\end{array}$ & $\begin{array}{l}\text { Total number of violent thefts } \\
\text { (robbery, hijacking, and/or violent) }\end{array}$ & $\begin{array}{l}\text { Percentage share of violent thefts } \\
\text { (robbery, hijacking, and/or violent) }\end{array}$ \\
\hline 2000 & 131 & 22 & 16.80 \\
2001 & 118 & 16 & 13.60 \\
2002 & 236 & 35 & 14.80 \\
2003 & 376 & 62 & 16.50 \\
2004 & 447 & 85 & 19.00 \\
2005 & 408 & 77 & 18.90 \\
2006 & 874 & 78 & 8.90 \\
2007 & 3963 & 246 & 6.20 \\
2008 & 4471 & 205 & 4.60 \\
2009 & 5087 & 219 & 4.30 \\
2010 & 3179 & 67 & 2.10 \\
2011 & 214 & 19 & 8.90 \\
Total & 19,504 & 1131 & 5.80 \\
\hline
\end{tabular}


Table 2 Descriptive statistics across months (all values in thousands of EUR)

\begin{tabular}{lllll}
\hline Month & Frequency & Total & Mean & Std. dev. \\
\hline J & 107 & 28,778 & 269 & 572 \\
F & 70 & 39,924 & 570 & 1450 \\
M & 82 & 37,033 & 452 & 1273 \\
A & 74 & 20,351 & 275 & 760 \\
M & 73 & 20,048 & 275 & 540 \\
J & 65 & 16,897 & 260 & 467 \\
J & 62 & 9984 & 161 & 260 \\
A & 62 & 42,909 & 692 & 2856 \\
S & 68 & 32,307 & 475 & 1746 \\
O & 78 & 19,717 & 253 & 564 \\
N & 82 & 19,946 & 243 & 332 \\
D & 70 & 33,406 & 477 & 759 \\
Total & 893 & 321,301 & & \\
\hline
\end{tabular}

Pairwise chi square tests with Bonferroni correction reveal that incident frequency is significantly higher in January than in June and July.

Table 3 displays descriptive statistics for different days of the week. As expected, there are large differences between the days. Hence, a more comprehensive analysis is needed. A Levene test reveals significant heteroscedasticity in the mean incident values $(\mathrm{L}=6.661, p<0.001)$. A Brown-Forsythe test reveals that different days of the week are characterized by significantly different mean incident values $(\mathrm{F}=2.592, p=0.018)$. Post-hoc analysis using pairwise t-tests with Bonferroni correction reveals that Monday has a significantly higher incident value than Tuesday. Finally, pairwise chi square tests with Bonferroni correction reveal that incident frequency is significantly lower on Saturdays and Sundays than on other days of the week.

Table 4 displays descriptive statistics for different transport chain locations. ${ }^{1}$ As expected, there are large differences between the locations. Hence, a more comprehensive analysis is needed. A Levene test reveals significant heteroscedasticity in the mean incident values $(\mathrm{L}=7.674, \mathrm{p}<0.001)$. Thus, a Brown-Forsythe test is used to compare the mean values across locations, but no significant difference is found $(\mathrm{F}=2.049, p=0.075)$. Finally, incident frequencies are significantly different across incident locations $(\chi 2=346.75, \mathrm{p}<0.001)$.

Table 5 displays descriptive statistics for different incident categories. As expected, there are large differences between the categories. Hence, a more comprehensive analysis is needed. A Levene test reveals significant heteroscedasticity in the mean incident values $(\mathrm{L}=2.539, p=0.019)$. A Brown-Forsythe test reveals that different incident categories are characterized by significantly different mean incident values $(\mathrm{F}=4.824, \mathrm{p}<0.001)$. Post-hoc analysis with Tamhane's T2 reveals that hijacking and

\footnotetext{
${ }^{1}$ The total values in Tables 4 and 6 differ from those in the other tables. The reason is that a few incidents were excluded because there was no information available regarding location and/or modus operandi.
} 
Table 3 Descriptive statistics across days of the week (all values in thousands of EUR)

\begin{tabular}{lllll}
\hline Day of the week & Frequency & Total & Mean & Std. dev. \\
\hline M & 142 & 90,148 & 635 & 2185 \\
T & 146 & 29,747 & 204 & 316 \\
W & 148 & 62,307 & 421 & 1315 \\
T & 150 & 52,072 & 347 & 636 \\
F & 150 & 35,659 & 238 & 486 \\
S & 79 & 16,058 & 203 & 456 \\
S & 78 & 35,311 & 453 & 1213 \\
Total & 893 & 321,301 & & \\
\hline
\end{tabular}

robbery have significantly higher incident values than "theft from facility," "theft from vehicle," and "lorry theft." Finally, incident frequencies are significantly different across incident categories $(\chi 2=944.42, \mathrm{p}<0.001)$.

Table 6 displays descriptive statistics for different MO. As expected, there are large differences between the categories. Hence, a more comprehensive analysis is needed. A Levene test reveals significant heteroscedasticity in the mean incident values $(\mathrm{L}=2.270, \mathrm{p}=0.019)$. Thus, a Brown-Forsythe test is used to compare the mean values across MO, but no significant difference is found $(\mathrm{F}=2.349, \mathrm{p}=0.075)$. Finally, incident frequencies are significantly different across incident $\mathrm{MO}\left(\chi^{2}=1613.7\right.$, $\mathrm{p}<0.001$ ).

Table 7 displays the different product categories which, according to the reports, have been stolen during violent cargo thefts.

\section{Discussion}

The use of violence in cargo theft may be increasing and thus following the general criminal trend in the EU (cf. EUICS 2005). However, analysis of the TAPA EMEA IIS data cannot confirm this apparent trend. Violent cargo thefts represent around 5-10\% of all thefts (Table 1 and IRU 2008). There are also seasonal variations in the use of a

Table 4 Descriptive statistics across locations (all values in thousands of EUR)

\begin{tabular}{lllll}
\hline Location & Frequency & Total & Mean & Std. dev. \\
\hline Non-secured parking & 237 & 52,234 & 220 & 425 \\
Secured parking & 13 & 5850 & 450 & 1074 \\
Third party facility & 99 & 37,327 & 377 & 667 \\
En route & 266 & 102,547 & 386 & 717 \\
Transport mode facility & 68 & 46,391 & 682 & 1781 \\
Supply chain facility & 158 & 45,257 & 286 & 1236 \\
Total & 841 & 289,607 & & \\
\hline
\end{tabular}


Table 5 Descriptive statistics across incident categories (all values in thousands of EUR)

\begin{tabular}{lllll}
\hline Incident category & Frequency & Total & Mean & Std. dev. \\
\hline Burglary & 242 & 51,121 & 211 & 534 \\
Hijacking & 212 & 100,125 & 472 & 995 \\
Robbery & 381 & 161,331 & 423 & 1528 \\
Theft from facility & 3 & 164 & 55 & 49 \\
Theft from vehicle & 33 & 1745 & 53 & 68 \\
Theft of vehicle & 20 & 6706 & 335 & 651 \\
Lorry Theft & 2 & 109 & 55 & 59 \\
Total & 893 & 321,301 & & \\
\hline
\end{tabular}

violent MO for cargo thefts. The variations are observed for particular months of the year and days of the week. According to the temperature aggression hypothesis (which suggests an increase of violent crimes during warmer periods), an increase in violent cargo crimes during the summer would be expected. However, as Table 2 shows, there are few significant differences between months. Interestingly, there is only one statistically significant difference (for $\mathrm{H} 2$ ): incident frequency is significantly higher in January than in June and July. If the mean losses from thefts are reviewed, the picture changes because four months (February, August, September, and December) show a higher loss per incident in the value of stolen goods and only July shows a decrease. With regard to total losses, five months show greater losses (February, March, and August and slightly fewer total losses in September and December) and only one month shows a noticeably low total loss, namely July. However, despite these easy-toread statistical differences, they are not statistically significant because the sample size is relatively small (Lantz 2013), which means that with the data used in this paper cannot either prove or disprove H1. Overall, it is possible to state that the temperature aggression hypothesis has low validity for understanding violence in cargo thefts. Nevertheless, the large difference (even if not statistically significant due to the small sample size) between July and August, in terms of frequency and mean losses, may indicate that the major reason for differences is not related to temperature variation. At this stage, we can, of course, only speculate what that systematic reason could be (if there actually is one), but possible factors might include social habits and practices

Table 6 Descriptive statistics across MO (all values in thousands of EUR)

\begin{tabular}{lllll}
\hline Modi operandi & Frequency & Total & Mean & Std. dev. \\
\hline Deception & 5 & 3713 & 743 & 1354 \\
Deceptive stop & 33 & 19,924 & 604 & 1236 \\
Forced stop & 43 & 14,671 & 341 & 473 \\
Internal & 3 & 3069 & 1023 & 924 \\
Intrusion & 242 & 45,567 & 188 & 487 \\
Violent & 549 & 222,868 & 406 & 1377 \\
Total & 875 & 309,813 & & \\
\hline
\end{tabular}


Table 7 Violent cargo thefts and different product categories (all values in thousands of EUR)

\begin{tabular}{|c|c|c|c|c|}
\hline Product category & Frequency & Total & Mean & Std. dev. \\
\hline Cash/bullion & 17 & 33,098 & 1946 & 4007 \\
\hline Clothing and footwear & 32 & 4093 & 127 & 178 \\
\hline Computer software & 5 & 3575 & 715 & 1370 \\
\hline Consumer electronics & 135 & 51,516 & 381 & 1928 \\
\hline Cosmetic and hygiene products & 28 & 6398 & 228 & 466 \\
\hline $\mathrm{CPU}$ & 28 & 32,882 & 1174 & 1934 \\
\hline Desktop, server, networking & 36 & 6966 & 193 & 222 \\
\hline Displays (monitors) & 26 & 4363 & 167 & 252 \\
\hline Food and beverage & 31 & 7154 & 230 & 402 \\
\hline HDD, storage & 3 & 1769 & 589 & 592 \\
\hline Laptops and PDAs & 65 & 14,179 & 218 & 418 \\
\hline Memory, RAM & 13 & 6225 & 478 & 709 \\
\hline Metal & 74 & 13,704 & 185 & 486 \\
\hline Mobile phones & 67 & 48,665 & 726 & 954 \\
\hline Non-electronic & 79 & 19,915 & 252 & 460 \\
\hline Peripheral (hardware) & 15 & 1245 & 83 & 132 \\
\hline Pharmaceutical and medical products & 4 & 6341 & 1585 & 2944 \\
\hline Sports goods & 6 & 1743 & 290 & 426 \\
\hline Supplies & 9 & 1714 & 190 & 106 \\
\hline Tobacco products & 86 & 20,256 & 235 & 496 \\
\hline Unspecified & 53 & 7266 & 137 & 272 \\
\hline Various IT & 79 & 28,114 & 355 & 812 \\
\hline Total & 891 & 321,181 & & \\
\hline
\end{tabular}

originating from holidays, fiscal years, institutional factors, and other reasons. These causes are known to influence retail trade and industrial production and might also affect the more organized and violent side of cargo crime.

Variation according to the day of the week with regard to violence provides an interesting picture. Incident frequency is significantly lower on Saturdays and Sundays than on other days, a finding that supports H4. In addition, Mondays have a significantly higher incident value than Tuesdays, a finding that supports H3. All other differences found between the days of the week are not statistically significant. Overall, it seems that the use of violence is generally confined to working days. This statement is based on the finding that only $18 \%$ of all thefts occur on Saturdays and Sundays. A review of mean losses and total losses provides a better picture because Monday appears as the most dangerous day with higher mean losses. The dataset used in this research does not indicate why this is the case. One possible explanation for increased losses on Monday is that is when the theft/ loss is discovered. However, this explanation is not valid because a violent crime focuses on someone being threatened; therefore, information about time and place is more accurate than for other reported cargo thefts (cf. Ekwall and Lantz 2013; Ekwall and Lantz 2015a; Ekwall and Lantz 2015b). 
A review of incident locations, categories, and MO shows many types of significant difference that were expected from a common sense perspective, even though the magnitudes were unclear. Interestingly, the most dangerous location is "en route," which represents $35 \%$ of total losses and the highest frequency of any single reported location. Further, locations outside facilities represent $61 \%$ of total thefts but only $55 \%$ of total loss value. This suggests that road transportation is vulnerable and therefore traditional methods of theft, such as non-violent theft, may be used by potential perpetrators. From an incident and modus operandi perspective, a review shows that when violence is used in cargo thefts, the mean loss value seems to be significantly higher, especially when compared to "theft from facility," "theft from vehicle," and "lorry theft." As to incident categories, robbery and hijacking both generate relatively high frequency (66\% of all thefts) but more importantly, higher mean losses ( $81 \%$ of all loss values) (see Table 5). With regard to modi operandi, the picture is a little different because from a frequency perspective, violence is involved in $63 \%$ of all thefts and $72 \%$ of all loss value. A review of the different stolen products shows which types of companies are members of TAPA EMEA because high value consumer goods are the most common general product type (see Table 7). It is not possible to make any other observations based on product type.

Altogether, these general findings about violent cargo theft point towards several interesting theoretical conclusions. Statistically, it can be stated that perpetrators who use violence seem to cause greater losses per theft than other types of modus operandi, particularly "deception" and "internal." It could be concluded that perpetrators respond to greater security with more violence, and by so doing, they need to steal goods of greater value because violence draws greater attention from the authorities. In addition, if convicted, the perpetrators can expect longer prison sentences. The most common type of violent cargo theft occurs on Mondays in January and involves robbing a lorry on the road and stealing consumer electronics.

The analysis of the TAPA EMEA IIS statistics regarding violent cargo thefts confirms the presence of seasonality and reveals different seasonal patterns across categories on yearly and weekly bases. Surprisingly, the main criminology theory for explaining seasonality with regard to violent crimes, the temperature aggression hypothesis, finds little support in this research. Nevertheless, the reasons behind seasonality on both a yearly and weekly basis may be found in either the seasonality of cargo transportation (volume, types of product, routes, storage decisions, etc.) or in the seasonality of perpetrators' willingness to commit these types of crime. Because there is no significant decrease in the number of thefts in any given month, but there is a decrease on Saturdays and Sundays (H4), this could be interpreted as the potential perpetrators preferring to "work" during the week and do other things during the weekends. This is just speculation, and with the data set forth in this paper, the statement cannot be confirmed or rejected.

From an SCD perspective, any type of cargo theft is interesting as it removes goods from the legal SC and sells the products to the, hopefully intended, end consumers. The illegal/stolen products make their way back to legal SCs, normally through flea markets, pawnshops, jewellers, websites, or second-hand stores, depending on who the sellers are (Johns and Hayes 2003). By doing this, the SC is hit twice as it first loses its products and later it also loses sales. It is possible to attribute the loss of market shares and sales to the poor protection of the products in the SC. The loss of goods due 
to violent $\mathrm{MO}$ only means larger losses, at any given incident, than other types of cargo thefts.

\section{Conclusion}

According to the TAPA EMEA IIS statistics, the number of cargo theft incidents that involve violence is relatively low, around $5 \%$ of total thefts. This should be compared with other sources, which claim that up to $10 \%$ of all cargo thefts involve violence (IRU 2008). The IRU (2008) study also concludes that $17 \%$ of lorry drivers have been robbed in the last five years, $30 \%$ more than once, and $21 \%$ have been physically assaulted (IRU 2008). Despite this, the data set forth in this paper suggests that the use of violence is still relatively rare. From an impact perspective, a violent MO generates higher direct losses per theft than most other types of MO. With regard to the total risk in relation to cargo theft, it seems that the road transportation industry should be concerned about violence because such an MO always generates higher direct losses and can also cause higher indirect costs, such as treatment for exposed personnel. The higher direct losses also lead to a higher likelihood for SCD as more products are lost at one particular event. This suggests that the risk for theft of certain products (see Table 7) also should be taken into account when a company is considering ways to reduce the general risk for SCD. Furthermore, the result in this paper shows that different transport chain locations have different likelihoods for violent cargo thefts, which means that the distribution chain needs to be considered in order to reduce the general risk of SCD. These results are consistent with previous research (Ekwall and Lantz 2016).

The seasonal effect on violent cargo crimes seems to be small, even if the data used in this paper supports three of the four hypotheses (H2, H3, and H4). However, within this understanding, there are only a few statistically significant differences found in the TAPA EMEA IIS data as to violence. The differences in the mean values of thefts across MO and incident types could indicate that crime often reflects the perpetrator's assessment of the crime's risk, the required effort, the potential payoff, the degree of peer support for the action, the risk of apprehension and punishment, and individual needs (Reppetto 1974; Clarke 1995). Generally, incident types such as hijacking and robbery (or "forced stop" and "violent") receive greater attention from the authorities, carry higher conviction risks, and lead to more severe punishments. The profit from a theft (the mean value of the stolen cargo) must be sufficiently high to cover the crime risk or cost as assessed by the perpetrator. Similar reasoning applies to incident categories such as deception and internal because they both require greater planning and execution abilities as indicated by the higher mean losses per incident.

\section{Implications for research}

As demonstrated in this paper, crime against the flow of goods is a real threat and must be considered in SCRM research. The, normally external (see Table 6), source of uncertainty of cargo crime, which can cause supply chain disruptions, needs to be included in future research. The two examples presented in the introduction of this paper illustrate a need to include cargo theft and the use of violence in SCRM research. 
The example of supply chain disruption caused by a violent modus operandi in cargo thefts means that the indirect costs related to any incident of theft clearly have the potential to surpass the direct costs many times over. In normal terms of strategies against SCD (safety buffers in time, capacity, and inventory), cargo theft removes goods (lowers available inventory), which may lead to a need for increased capacity, and if the goods are stolen at the wrong places, there is no time left to distribute the goods. Further, both examples given in this paper provided a direct link between a cargo theft incident and the insurance service provider. Therefore, analyzing this type of problem in a supply chain context should include integrated service providers (ISPs), as well as LSPs, because the former are directly involved with other parties. This would lead to a discussion about liability because the parties would try to share (or refuse) the costs of theft with other parties (cf. Ekwall and Nilsson 2008).

We can only speculate about the reasons for the seasonality of violent cargo thefts. Possible reasons for this phenomenon include variations in the type of goods, offenders, transport volumes, and/or the number of offenders. The reason for such seasonality should be addressed in future research using other data sources. This paper also highlights the need for an interdisciplinary approach in order to understand the effects of crime from a risk perspective.

\section{Implications for practitioners}

The knowledge that perpetrators may specialize in a certain method of theft in order to maximize their results could aid the development of managerial approaches to security. According to various businesses, the incidence of thefts increases during the "Christmas rush" period; that is, the period just before Christmas. However, our results do not support this observation. We suggest that there is a post-Christmas rush increase in the number of thefts and a similar increase in late summer (August). Businesses also assert that thefts increase on weekends; however, this observation is also unsupported by our results, although other sources indicate that there are more thefts on weekends (FreightWatch 2012; Burges 2013). As violent cargo theft can be considered an external $\mathrm{SCD}$, the internal managerial decision-making process must consider cargo theft when developing preventive measures (cf. Lorentz and Hilmola 2012). In other words, involved organizations need to consider the risk for cargo theft in order to apply the right security at the right transport chain location for the riskiest products and should also consider parallel distribution channels in order to avoid SCD impacts after a major cargo theft incident.

The latter issue needs more attention from researchers and logistics companies. The results of this paper support the conclusions of prior studies (Ekwall 2009; Ekwall 2010; Ekwall and Lantz 2013) in that perpetrators (specifically, their actions and decision triggers) need to be included in the analysis of cargo theft (cf. Guthrie and Guthrie 2006). This is a straightforward conclusion; however, the current trend in SCRM research is to exclude criminal threats other than terrorism to supply chains (Sheffi 2001; Christopher and Lee 2004; Khan and Burnes 2007; Rao and Goldsby 2009; Lorentz and Hilmola 2012; Ghadge et al. 2013; Lee and Rha 2016).

Funding This research was conducted with the financial support from the Peter Wallenberg Foundation. 
Open Access This article is distributed under the terms of the Creative Commons Attribution 4.0 International License (http://creativecommons.org/licenses/by/4.0/), which permits unrestricted use, distribution, and reproduction in any medium, provided you give appropriate credit to the original author(s) and the source, provide a link to the Creative Commons license, and indicate if changes were made.

\section{References}

Aastrup J, Halldórsson A (2008) Epistelmological role of case studies in logistics: a critical realist perspective. Int J Phys Distrib Logist Manag 38:746-763

Anderson CA, Bushman BJ, Groom RW (1997) Hot years and serious and deadly assault: empirical tests of the heat hypothesis. J Pers Soc Psychol 73:1213-1223

Anderson CA, Anderson KB, Dorr N, DeNeve KM, Flanagan M (2000) Temperature and aggression. In: Zanna M (ed) Advances in experimental social psychology. Academic Press, New York, pp 63-133

Bamfield J (2004) Shrinkage, shoplifting and the cost of retail crime in Europe: a cross-sectional analysis of major retailers in 16 European countries. Int J Retail Distrib Manag 32:235-241

Bamfield J (2006) Sed quis custodiet? Employee theft in UK retailing. Int J Retail Distrib Manag 34:845-859

British Retail Consortium (2009) 9th Retail Crime Survey. British Retail Consortium, London

Burges D (2013) Cargo theft, loss prevention, and supply chain security. Butterworth-Heinemann, Oxford

Chapman P, Christopher M, Juttner U, Peck H, Wilding R (2002) Identifying and managing supply chain vulnerability. Logistics \& Transport Focus 4(4):59-64

Christopher M, Lee H (2004) Mitigating supply chain risk through improved confidence. Int J Phys Distrib Logist Manag 34:388-396

Clarke RV (1995) Situational crime prevention. In: Tonry M and Farrington DP (eds). Building a safer society: strategic approaches to crime prevention. University of Chicago Press, Chicago

Cohen J (1941) The geography of crime. Annals 217:29-37

Colicchia C, Strozzi F (2012) Supply chain risk management: a new methodology for a systematic literature review. Supply Chain Manag: Int J 17:403-418

Ekwall D (2009) Managing the risk for antagonistic threats against the transport network. Division of Logistics and Transportation, Chalmers University of Technology, Göteborg

Ekwall D (2010) On analyzing the official statistics for antagonistic threats against transports in EU: a supply chain risk perspective. J Transp Secur 3:213-230

Ekwall D, Lantz B (2013) Seasonality of cargo theft at transport chain locations. Int J Phys Distrib Logist Manag 43:728-746

Ekwall D, Lantz B (2015a) Cargo theft at non-secure parking locations. Int J Retail Distrib Manag 43:204-220

Ekwall D, Lantz B (2015b) Modi operandi and incident categories for cargo theft in EMEA - a seasonality analysis. J Transp Secur 8:99-113

Ekwall D, Lantz B (2016) Supply chain risk analysis and assessment - a cargo theft example. Transp J 55: $400-419$

Ekwall D, Nilsson F (2008) Using business complexity to handle supply chain risk: dealing with borders of cargo liability. In: Proceedings of Nofoma 2008, Helsinki

EP - European Parliament's Committee on Transport and Tourism (2007) Organised theft of commercial vehicles and their loads in the European union. European Parliament, Brussels

EU (2003) Freight transport security. Consultation paper. European Commission, Brussels

European Conference of Ministers of Transport ECMT (2001) Theft of goods and goods vehicles. CEMT/CM (2001)19 Lissabon

Europol (2009) Cargo theft report: Applying the brakes to road cargo crime in Europe. Europol, The Hague Falk JJ (1952) The influence of the seasons on the crime rate. J Crime Law Criminol 43:199-213

FreightWatch (2012) FreightWatch international global threat assessment. FreightWatch, Austin

FWI SCIC (2015) Europe intelligence note. FreightWatch, supply chain intelligence center

Ghadge A, Dani S, Chester M, Kalawsky R (2013) A systems approach for modelling supply chain risks. Supply Chain Manag: Int J 18:523-538

Gorr W, Olligschlaeger A, Thompson Y (2003) Short-term forecasting of crime. Int J Forecast 19:579-594

Guthrie J, Guthrie A (2006) A research agenda for loss prevention. Int J Retail Distrib Manag 34:873-878

Hylleberg S (1995) Modelling seasonality. Oxford University Press, Oxford

IRU (2008) Attacks on drivers of international heavy goods vehicles. International Road Transport Union, Secretariat General, Geneva 
Johns T, Hayes R (2003) Behind the fence: buying and selling stolen merchandise. Secur J 16:4

Karlsson A (2014) DB Schenker stoppar leveranser till Rinkeby. http://www.Transportnet.se. Accessed 15 Sept 2014 (in Swedish)

Khan O, Burnes B (2007) Risk and supply chain management: creating a research agenda. Int J Logist Manag 18(2):197-216

Lantz B (2013) The large sample size fallacy. Scand J Caring Sci 27:487-492

Lawrence G (2004) Designing out crime: the retail perspective. Int J Retail Distrib Manag 32:572-576

Lee SM, Rha JS (2016) Ambidextrous supply chain as a dynamic capability: building a resilient supply chain. Manag Decis 54:2-23

Levy D (1995) International sourcing and supply chain stability. J Int Bus Stud 26(2):343-360

Lorentz H, Hilmola OP (2012) Confidence and supply chain disruptions. J Modell Manag 7:328-356

Machalaba D, Kim Q (2002) West Coast docks are shut down after series of work disruptions. Wall Street J (Eastern Edition) 20 September 2002

Manuj I, Mentzer JT (2008) Global supply chain risk management. J Bus Logist 29:133-155

Mitroff I, Alpasan MC (2003) Preparing for evil. Harv Bus Rev 81:109-115

Muralidharan C, Anantharaman N, Deshmukh S (2001) Vendor rating in purchasing scenario: a confidence interval approach. Int J Oper Prod Manag 21:1305-1326

Norrman A, Jansson U (2004) Ericsson's proactive supply chain risk management approach after a serious sub-supplier accident. Int J Phys Distrib Logist Manag 34:434-456

Rabinovich E, Cheon S (2011) Expanding horizons and deepening understanding via the use of secondary data sources. J Bus Logist 32:303-316

Rao S, Goldsby TJ (2009) Supply chain risks: a review and typology. Int J Logist Manag 20:97-123

Reppetto TA (1974) Residential crime. Ballinger, Cambridge

Rice J, Caniato F (2003) Building a secure and resilient supply network. Supply Chain Manag Rev 7:22-30

Riddalls C, Bennett S (2002) Production-inventory system controller design and supply chain dynamics. Int J Syst Sci 33:181-195

Saunders R (2008) Increasing our vigilance. A presentation at TAPA Q1, Warwick

Sheffi Y (2001) Supply chain management under the threat of international terrorism. Int J Logist Manag 12: $1-11$

Stock JR (1997) Applying theories from other disciplines to logistics. Int J Phys Distrib Logist Manag 27:515539

Tavares C, Thomas G (2009) Population and social conditions. Eurostat criminal and criminal justice, Statistics in focus 36/2009

TruckPol (2007) TruckPol annual report 2007. Homeoffice, TruckPol, UK

Tummala R, Schoenherr T (2011) Assessing and managing risks using the supply chain risk management process (SCRMP). Supply Chain Manag: Int J 16:474-483

UN-CTS (2010) United Nations survey of crime trends and operations of criminal justice systems - eleventh round. UN, New York

Van der Vorst J, Beulens A (2002) Identifying sources of uncertainty to generate supply chain redesign and strategies. Int J Phys Distrib Logist Manag 32:409-430

van Dijk JJM, Manchin R, van Kesteren J, Nevala S, Hideg G et al (2006) The burden of crime in the EU: a comparative analysis of the European Crime and Safety Survey (EU ICS) 2005. Gallup Europe, Brussels

van Marle G (2015) More hotspots for violent freight crime in Europe as mafia gangs see the potential. The Loadstar. https://theloadstar.co.uk/hotspots-violent-freight-crime-europe-mafia-gangs-see-potential/. Accessed 19 Dec 2017

Vidal C, Goetschalckx M (2000) Modeling the effects of uncertainties on global logistics systems. J Bus Logist 21:95-120

Wagner SM, Bode C (2008) An empirical examination of supply chain performance along several dimensions of risk. J Bus Logist 29:307-325

Wilding R (1998) The supply chain complexity triangle: uncertainty generation in the supply chain. Int J Phys Distrib Logist Manag 28:599-616

Wu T, Blackhurst J, O'grady P (2007) Methodology for supply chain disruption analysis. Int J Prod Res 45: $1665-1682$ 